\title{
CHEMICAL MODIFICATIONS OF NANOSTRUCTURED TITANIA-BASED MATERIALS IN PHOTOCATALYTIC DECOMPOSITION/CONVERSION OF VARIOUS ORGANIC POLLUTANTS: A SHORT REVIEW
}

Aleksandra Krstić, Hristina Stanković, Miljana Rubežić, Marija Vasić, Aleksandra Zarubica*

Faculty of Science and Mathematics, University of Niš, Serbia

Titanium dioxide, as environmental (decontamination) photocatalyst, is increasingly gaining importance in the removal of organic pollutants from water and air, as well. Different methods can be used for obtaining $\mathrm{TiO}_{2}$ catalyst, but sol-gel and hydrothermal methods are most commonly used for the synthesis and modification of $\mathrm{TiO}_{2}$. The properties of nanostructured materials such as crystal phase, surface features and electronic structures can be changed with doping. In this paper, the influence of $\mathrm{Fe}$ and $\mathrm{Zn}$ as dopants on the physico-chemical properties of $\mathrm{TiO}_{2}$ catalyst will be presented based on the reported literature data. Usually applied instrumental techniques for the materials characterizations are X-ray diffraction (XRD), SEM, TEM, FTIR and UV-vis spectroscopy. The removal efficiency of various organic pollutants (organic dyes, antibiotics, pesticides, xenobiotics) is determined by the characteristics and dosage of the catalyst, nature and initial concentration of pollutants, $\mathrm{pH}$, oxidants addition, light intensity and wavelength.
(REVIEW ARTICLE)

UDC 544.526.5:549.514.6+66.017

Keywords: Iron, Hydro-thermal synthesis, Photocatalysis, Sol-gel, Titania, Zinc

\section{Introduction}

Titanium dioxide $\left(\mathrm{TiO}_{2}\right)$ has attracted a lot of attention in recent decades. $\mathrm{TiO}_{2}$, as a wide band-gap semiconductor, shows very good optical, electrical, mechanical and catalytic properties, which makes it an excellent material for environmental refinement. $\mathrm{TiO}_{2}$ can be used for the decomposition of environmental pollutants as a possible alternative to conventional waste water treatment technologies [1]. Titania is highly studied due to its specific characteristics such as high thermal and chemical stability, non-toxicity, chemical and biological inertness, cost-effectiveness, high photocatalytic activity and strong oxidizing/reducing behavior(s). Photocatalytic activity of $\mathrm{TiO}_{2}$ is based on its semiconductor properties [2]. The band gap of titania is about $3.2 \mathrm{eV}$, and it occurs in three main different polymorphic phases: rutile (tetragonal, $3.02 \mathrm{eV}$ ), anatase (tetragonal, $3.2 \mathrm{eV}$ ) and brookite (ortorhombic) [3]. Thermo-chemically, the most stable polymorphic phase of these three mentioned phases is rutile. The other two polymorphic phases, anatase and brookite, can be transformed to rutile at elevated temperatures. When the $\mathrm{TiO}_{2}$ photocatalyst is illuminated with light of the corresponding wavelength, where light photon energy should be equal or greater than the energy of the band gap of the semiconductor, photocatalytic reactions are activated. In this way, the electrons $\left(\mathrm{e}^{-}\right)$are induced and they migrate from the valence band to the conduction band. In the valence band, positive holes are generated $\left(h^{+}\right)$, and electrons $\left(\mathrm{e}^{-}\right)$migrate to the conduction band. Therefore, in the semiconductor, under the influence of light, electron/hole pairs are formed $[4,5]$.
Due to the wide band gap of titania, its use is highly limited because of the necessity for the UV-radiation application in photocatalytic processes in environmental treatment processes [6]. Scientists have tried in various ways to adjust the band gap, and thus enable the activation of $\mathrm{TiO}_{2}$ by using the visible part of the spectrum. These different ways can be: the addition of electron donors (so called: hole scavengers), the addition of transition metal ions (in)to titania, sensitizing using dye molecules, etc. [6].

Low photocurrent efficiency of $\mathrm{TiO}_{2}$ could be overcome by the synthesis of ordered structures of $\mathrm{TiO}_{2}$ or by doping of $\mathrm{TiO}_{2}$ nanoparticles with transition metal ions [4,7]. Iron is a very interesting transition metal which was often used as dopant, and a large number of papers have been published on this subject. Also, Qiao et al. [8] have proven that a small amount of $\mathrm{Zn}^{2+}$ ions improved the separation of the charges, while the possibility of recombination significantly reduced [8].

This paper is a short review on published researches on the synthesis of $\mathrm{TiO}_{2}$-based nanopowders, psysico-chemical properties and the application in selected photocatalytic reactions.

Titania-based material preparation

Selection of precursors

Most commonly used substances as precursors for $\mathrm{TiO}_{2}$ synthesis are titanium tetrachloride $\left(\mathrm{TiCl}_{4}\right)$, titanium sulfate and then titanium isopropoxide and/or titanium tetrabutoxide

\footnotetext{
*Author address: Aleksandra R. Zarubica, Department of Chemistry, Faculty of Science and Mathematics, University of Niš,

Višegradska 33, 18000 Niš, Serbia

E-mail: zarubica2000@yahoo.com

The manuscript received: November, 5, 2018.

Paper accepted: November, 27, 2018.
} 
as alcoxide precursors. However, usages of most of these precursors have certain limitations that are proven in practice. For example, $\mathrm{TiCl}_{4}$ is problematic for handling because of its property to fume easily. The use of alkoxides in synthesis of titania requires strict control of experimental conditions such as air humidity, $\mathrm{pH}$ and temperature. It is known that when alkoxide is used as a precursor, an intense hydrolysis of alkoxide is possible in the air so this is a disadvantage of these precursors usage. Additionally, the commercialization of this process is limited due to high prices of alkoxides. When titanium(IV)-sulfate is used as a precursor, $\mathrm{TiO}_{2}$ obtained in this case shows a lower catalytic activity compared to the $\mathrm{TiO}_{2}$ catalyst obtained with the use of titanium tetraisopropoxide and/or titanium chloride as precursors $[9,10]$.

Goswami and Nath Ganguli [9] reported that the use of precursor potassium hexafluorotitanate in obtaining titania showed better properties than other precursors. Potassium hexafluorotitanate is very stable, water soluble, non-corrosive and it's not toxic for the environment. Moreover, the product itself and its degradation products are nontoxic [9]. Significant improvements in the reported process by using the cited precursor $\mathrm{K}_{2} \mathrm{TiF}_{6}$ are:

(i) Water is used as the process solvent that greatly reduces the costs of the process, because water is a cheap solvent, it is not toxic and it is ecologically-friendly,

(ii) A "gel"-like matter rather than a simple precipitate is formed,

(iii) After a thermal decomposition of the "gel"-like matter, the precursor material is obtained and in most cases it provides the production of homogeneous oxide material [9].

Different syntheses methods can be used for obtaining of the TiO2 catalyst such as: sol-gel [2,11-14], hydrothermal [15], solvothermal [14], the ultrasonic procedure, combining a sol-gel method with a hydrothermal treatment, combining a sol-gel method with a solvothermal treatment [14], the micro-emulsion formation procedure [16], the preparation procedure in flame aerosol reactors [17]. Among them, frequently used methods are sol-gel and hydrothermal method, and therefore they will be observed in this mini review paper.

\section{Process parameters in the preparation procedure}

The sol-gel method has become an increasingly important process for the synthesis of $\mathrm{TiO}_{2}$-based catalyst in recent years, and it has many advantages in obtaining some specific materials and biomaterials with outstanding properties as electric, optoelectronic, magnetic and bioactive [4]. This method provides the obtaining of titania-based catalysts in the form of powder(s) and thin films, as well. In addition, it is possible to control the size of particles and surface properties of the catalyst by using a sol-gel synthesis method. This is a relatively simple method for the synthesis of catalysts/materials with a relatively high chemical purity and homogeneity without the additional use of high temperature treatments or pressure [18]. Organic and inorganic precursors can be used in sol-gel synthesis route. In both cases, mono-dispersions powders characterized with submicron-sizes can be obtained. In the case when inorganic precursors such as titanile sulfate $\left(\mathrm{TiOSO}_{4}\right)$ or titanium chloride $\left(\mathrm{TiCl}_{4}\right)$ are used in the presence of sodium sulfate $\left(\mathrm{Na}_{2} \mathrm{SO}_{4}\right)[19,20]$, or tartaric acid [21], after the thermo(hydro)lysis, in both cases, particles of spherical shapes are obtained with diameters around $0.4 \mathrm{~nm}$. However, organic precursors for obtaining $\mathrm{TiO}_{2}$ are significantly more frequently used. The precursor undergoes two main reactions: hydrolysis and condensation. Hydrolysis and polycondensation occur at the same time as competitive reactions. There are many factors that can change a relative rate of the mentioned reactions, and the most important factors are: a type of the precursor and solvent, the ratio of water to the catalyst precursor, $\mathrm{pH}$ value, temperature, and a presence of additives [22].

Ward and Ko [22] showed that the sol-gel method is a very useful method for obtaining catalytic materials. Because of great potential for the use of titania and corresponding products in various areas, Ward and Ko have worked to improve this method, and thus improve the physical and chemical properties of these materials [22]. They obtained $\mathrm{TiO}_{2}$ gels by dissolving sodium titanate in concentrated $\mathrm{HCl}$, after which they added $\mathrm{K}_{2} \mathrm{CO}_{3},\left(\mathrm{NH}_{4}\right)_{2} \mathrm{CO}_{3}$ or $\mathrm{Na}_{2} \mathrm{CO}_{3}$ to avoid significant changes in $\mathrm{pH}$, or by using thermo(hydro) lysis of $\mathrm{TiCl}_{4}$ or $\mathrm{TiO}\left(\mathrm{NO}_{3}\right)_{2}$ under acid conditions. Depending on $\mathrm{pH}$ value and the nature of the counter-ions, in this way the colloidal particles obtained at same temperatures may have an anatase or a rutile crystal structure [22,23].

Lately, most researches are based on the use of alkoxides $\mathrm{Ti}(\mathrm{OR})_{4}$ as precursors for the sol-gel synthesis of $\mathrm{TiO}_{2}$. For the synthesis of $\mathrm{TiO}_{2}$ gels, Crisan et al. [24] used alkoxides $\mathrm{Ti}(\mathrm{OR})_{4}$ as precursors, where $\mathrm{R}$ is an organic radical such as ethyl (Et), propyl ( $n$-Pr), isopropyl (i-Pr), $n$-butil ( $n$ $\mathrm{Bu})$, and secondary butyl (s-Bu). Further, in the sol-gel synthesis substechiometric hydrolysis ratios and inorganic acids such as $\mathrm{HCl}$ and $\mathrm{HNO}_{3}$ are used. In this way, catalysts with uniform particles and with a large specific surface area are obtained [24].

Goswami and Nath Ganguli [9] have proposed precursor potassium hexafluorotitanate for the production of $\mathrm{TiO}_{2}$, the usage of which showed much better properties. These researchers dissolved $\mathrm{K}_{2} \mathrm{TiF}_{6}$ in distilled water and after that, this aqueous solution hydrolyses and formed a precipitate after the treatment with $\mathrm{NH}_{4} \mathrm{OH}$ solution to $\mathrm{pH} 7.5$ under constant stirring, in a Teflon baker, at room temperature. The resulting precipitate was filtered and washed with distilled water to a negative reaction to fluoride ions. After that, the precipitate was dispersed in hot water and the addition of $10 \% \mathrm{HNO}_{3}$ solution caused peptization. Hydrothermal treatment was performed in a Teflon lined stainless steel autoclave at the appropriate temperature. In this way, the $\mathrm{TiO}_{2}$ catalyst with the (relatively) good specific surface area, anatase crystal phase and $3.19 \mathrm{eV}$ band gap is obtained [9]

Apart from the sol-gel method, a hydrothermal method for the synthesis of $\mathrm{TiO}_{2}$ is also often used. Hydrothermal synthesis can be defined as a heterogeneous chemical reaction in the presence of an aqueous solvent, at elevated temperatures and pressures, in a closed system. This method can also be used for treatments of compounds that are relatively insoluble or unstable in water/air under ordinary/ normal conditions. The most commonly used precursors in 
this synthesis are titanium-based alkoxides. They are activated with acids or bases before the thermal treatment in autoclaves [25,26]. In their research, Byrappa and Adschiri [26] concluded that with the use of hydrothermal method $\mathrm{TiO}_{2}$ powder can be obtained that is characterized with different microstructures, morphologies and different crystal phase compositions by varying the following parameters: temperature, pressure, the duration of the process, the concentration of precursors and $\mathrm{pH}$ [26].

Lu et al. [27] have studied the effect of $\mathrm{pH}$ on the features of $\mathrm{TiO}_{2}$ powder obtained using a hydrothermal method, and they concluded that in the acidic $\mathrm{pH}$ range $(\mathrm{pH}<6)$ mixed phases of $\mathrm{TiO}_{2}$, brookite and anatase were obtained; on the contrary, if the conditions were alkaline, a pure anatase form of the $\mathrm{TiO}_{2}$ was obtained by using different temperatures below $230^{\circ} \mathrm{C}$ [27]. Phan et al. [28] have proved in their research that using a simple hydrothermal method in the presence of concentrated hydrochloric acid, the control of morphological properties of the obtained $\mathrm{TiO}_{2}$ can be carried out; in case when the preparation started from metallic $\mathrm{Ti}$ and hydrogen peroxide over hydrothermal oxidation, ultrafine powders of titania can be obtained [28]. In addition to numerous advantages mentioned above, a negative side is the limitation on the exclusive preparation/production of oxide powders.

\section{Modification of $\mathrm{TiO}_{2}$}

Doping is one of the most effective way(s) to change the properties of nanostructured materials such as crystal phase, surface and electronic structures. Doping is the process of the controlled addition of impurities, mainly ionic species in very small quantities into the corresponding base material. If a large amount of dopant ions is added to the material, the crystalline structure of the material can be disturbed, and a second crystal structure or mixed structures can be formed [29]. A group of scientists announced that the addition of various transition metal $(\mathrm{M})$ ions to titania is the best way to adjust/reduce the band gap, as well as the increase of the specific surface area of the nanostructured $\mathrm{TiO}_{2}$. Also, the addition of transition metal ions improves the photocatalytic activity of $\mathrm{TiO}_{2}$ that is an important purpose of doping [6]. For the purpose of gaining a highly active $\mathrm{TiO}_{2}$ catalysts, various transition metals are used as dopants such as: $\mathrm{Fe}^{3+}, \mathrm{Ag}^{+}$, $\mathrm{Cu}^{2+}, \mathrm{Zn}^{2+}, \mathrm{Cr}^{3+}, \mathrm{Mn}^{2+}$, and $\mathrm{Co}^{2+}$ ions [18]. In this mini review paper, the results obtained in various studies on the influence of iron and zinc as dopants of $\mathrm{TiO}_{2}$ will be presented.

A group of authors synthesized titanium dioxide nanopowders doped with different amounts of $\mathrm{Fe}^{3+}$ ions by a modified acid-catalyzed sol-gel method in non-aqueous medium. Sols were mechanically stirred for 10 minutes, sealed and placed at room temperature. After 5 days, gels were dried at $60{ }^{\circ} \mathrm{C}$ for $24 \mathrm{~h}$ and then the samples were calcined at 400 ${ }^{\circ} \mathrm{C}$ for $2 \mathrm{~h}$ [7]. All the iron-doped catalysts samples obtained in this way have lower band gap values compared to pure anatase (characterized with $3.2 \mathrm{eV}$ ). According to the results of these scientists, doping with $\mathrm{Fe}^{3+}$ ions increases the adsorption in a visible light zone. Also, the degradation rate of pollutants increases with increasing the amount of iron ions used as dopants [7].
Seabra et al. [2] used titanium(IV)-isopropoxide, zinc nitrate hexahydrate and iron nitrate nonahydrate as precursors for the sol-gel synthesis. Undoped and doped $\mathrm{TiO}_{2}$ powders were prepared in the following manner: titanium isopropoxide and the solution of absolute ethanol were sonicated and then distilled water was added. After sonication, ammonium hydroxide was added and sonicated again. Doped $\mathrm{TiO}_{2}$ powders were prepared in the same way. The iron and zinc precursors were dissolved in the chosen amount of distilled water. The final solutions were centrifuged, after that the obtained powders were dried and calcined at $500{ }^{\circ} \mathrm{C}$. In the structure of un-doped $\mathrm{TiO}_{2}$, after the thermal treatment, anatase was the main crystalline phase, but the presence of the rutile phase was also detected. When doped $\mathrm{TiO}_{2}$ samples were analyzed by XRD technique (Fe and $\mathrm{Zn}$ - doped $\mathrm{TiO}_{2}$ ), anatase was the only detected crystaline phase. Also, $\mathrm{Fe}$ and $\mathrm{Zn}$ doped titania-based powders were more uniform in size and characterized with smaller particles sizes than undoped $\mathrm{TiO}_{2}$ powders. As far as photocatalytic activities were concerned, it was observed that the photocatalytic activity of the catalyst was reduced if Fe was used as a dopant. However, titania doped with zinc showed a significantly higher photocatalytic activity [2].

Delekar et al. [6] have successfully synthesized a pure anatase phase of iron-doped $\mathrm{TiO}_{2}$ nanoparticles by a simple sol-gel method at room temperature. In this manner, synthesized and modified $\mathrm{TiO}_{2}$ showed an improved absorption of a visible light under UV-vis irradiation, the photocatalytic reaction was effectively initiated. Fe-doped $\mathrm{TiO}_{2}$ showed the improved photocatalytic activity in comparison to pure $\mathrm{TiO}_{2}$ due to lower band-gap energy [6].

\section{Physico-chemical characterisation(s)}

In order to characterize the synthesized titania-based materials, various techniques can be used such as: X-ray diffraction (XRD) technique, transmission electron microscopy (TEM), scanning electron microscopy (SEM), Fouriertransformed Infrared Spectroscopy (FTIR).

Using the X-ray diffraction (XRD) technique, the phase composition of the synthesized $\mathrm{TiO}_{2}$ nanopowders can be determined, after which the assessment of microstructural parameters can be performed: lattice parameters, crystallite size, etc. [30]. XRD patterns of the chosen obtained $\mathrm{TiO}_{2}$ powders are shown in Figure 1. As shown in Figure 1., into the un-doped $\mathrm{TiO}_{2}$ powders calcined at $500{ }^{\circ} \mathrm{C}$, anatase is the main crystalline phase, while the presence of rutile can also be detected in smaller volume fractions. However, in titania-based samples doped with iron and zinc, the only detected crystalline phase was anatase, while a rutile crystal phase was not registered. When iron was used as a dopant into/onto titania, the published results showed a decrease of the powder crystallinity (inset in Figure 1.) [2]. 


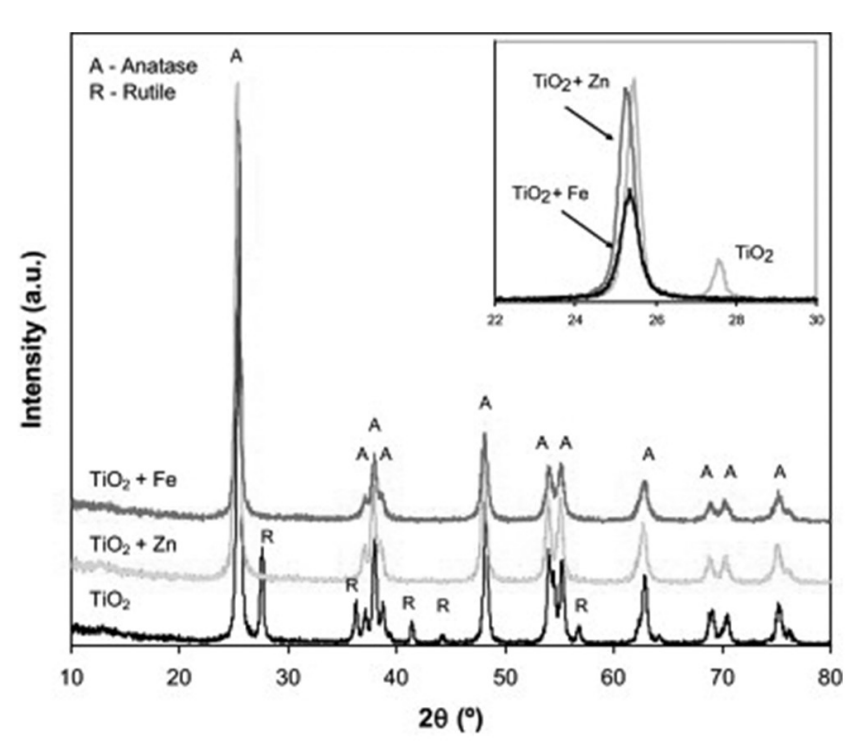

Figure 1. XRD spectra of titania-based powders [2]
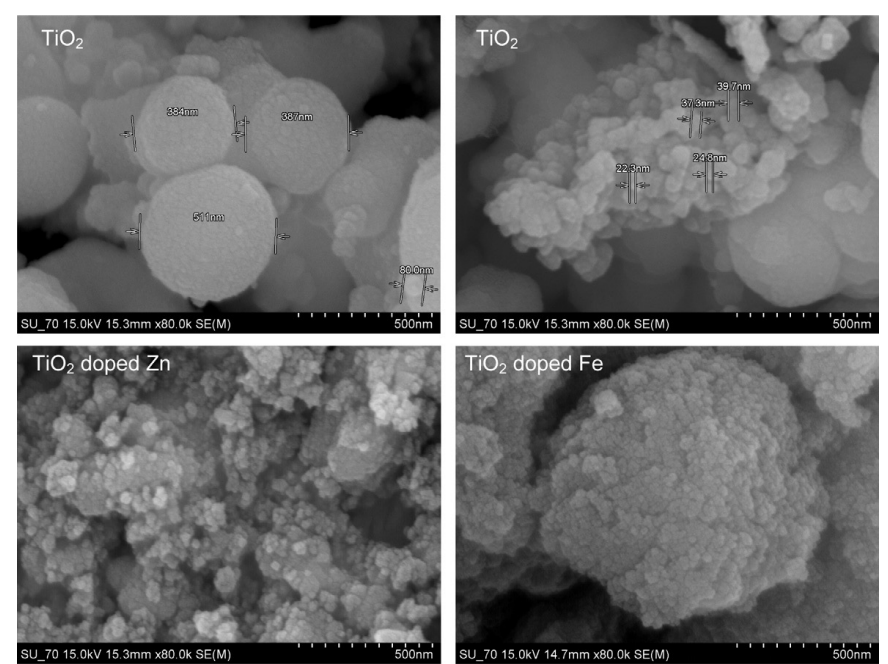

Figure 2. SEM images of pure $\mathrm{TiO}_{2}$ and titania doped with $\mathrm{Zn}$ and $\mathrm{Fe}[2]$

TEM provides information about the material morphology at higher resolution, while SEM can be used in characterization of the material morphology at smaller resolution. A group of scientists, Seabra et al. [2] have synthesized $\mathrm{TiO}_{2}$ powders by the sol-gel route and the particle sizes of the prepared powders were submicron (Figure 2.). The undoped titania showed the bi-modal distribution of particles sizes: fine particles (20$40 \mathrm{~nm}$ ) together with grainier/bigger ones (300-500 nm). The particles of $\mathrm{Zn}$ and Fe-doped $\mathrm{TiO}_{2}$ samples were characterized with smaller particles $(<40 \mathrm{~nm})$ and more uniform in size than the particles of undoped samples. Therefore, the specific surface areas (SSA) of the doped titania-based materials were higher than of the undoped $\mathrm{TiO}_{2}$ materials. On the other side it has also been reported that doped $\mathrm{TiO}_{2}$ powders tended to agglomerate with was more evident for the iron-doped titania (Figure 2.) with agglomerates around $1000 \mathrm{~nm}$ in diameter. The specific surface area after doping increased from $7 \mathrm{~m}^{2} / \mathrm{g}$ for undoped $\mathrm{TiO}_{2}$ to $15 \mathrm{~m}^{2} / \mathrm{g}$ and 41 $\mathrm{m}^{2} / \mathrm{g}$ for Fe and $\mathrm{Zn}$ doped $\mathrm{TiO}_{2}$, respectively [2].

In Figure 3, the FT-IR spectra of $0.0 \mathrm{~mol} \%, 1.0 \mathrm{~mol} \%$ and $3.0 \mathrm{~mol} \% \mathrm{Fe}$ to bare $\mathrm{TiO}_{2}$ samples are shown. All samples have been characterized with similar FTIR spectra. A broad peak observed between 3500 and $2800 \mathrm{~cm}^{-1}$ is assigned to a stretching vibration mode of the $-\mathrm{OH}$ group on the surface titanium centers of $\mathrm{TiO}_{2}$. The anatase $\mathrm{TiO}_{2}$ sample has been characterized with a broad band in the $400-900 \mathrm{~cm}^{-1}$ region, and in the investigation of this group of scientists, the FTIR spectra of all titania samples match with those spectra typical for the anatase titania crystal phase [6].

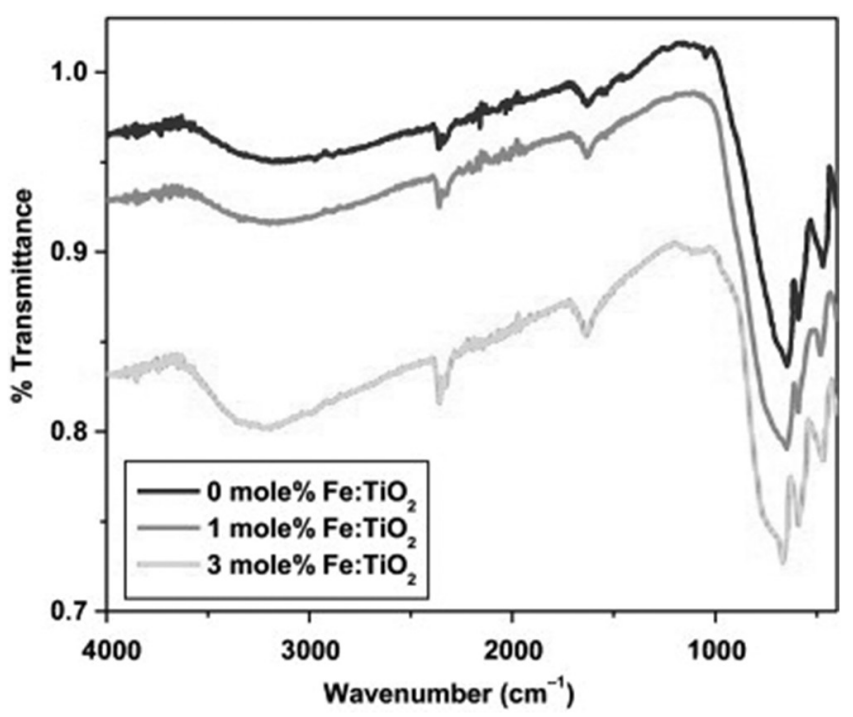

Figure 3. FTIR spectra of $\mathrm{TiO}_{2}$ and $\mathrm{Fe}$-doped $\mathrm{TiO}_{2}$ nanoparticles [6]

UV-vis spectra of the representative Fe-doped $\mathrm{TiO}_{2}$ samples are shown in Figure 4. Delekar et al. [6] have successfully synthesized a pure anatase phase of irondoped $\mathrm{TiO}_{2}$ nanoparticles with the improved photocatalytic activity in comparison to pure $\mathrm{TiO}_{2}$ because of lower band-gap energy [6]. Doping of iron into the $\mathrm{TiO}_{2}$ lattice provided a lower band gap. The increase of absorption in a visible region with a decrease in a band gap can be assigned to the formation of dopant (energy) level near to the valance band. The determination/estimation of optical properties of the doped titania-based samples resulted in the color change of doped powders from light to dark yellow. The presented results showed that photocatalytic performance of doped catalysts increased with the increase of the dopant amount (Figure 5.) [6]. 


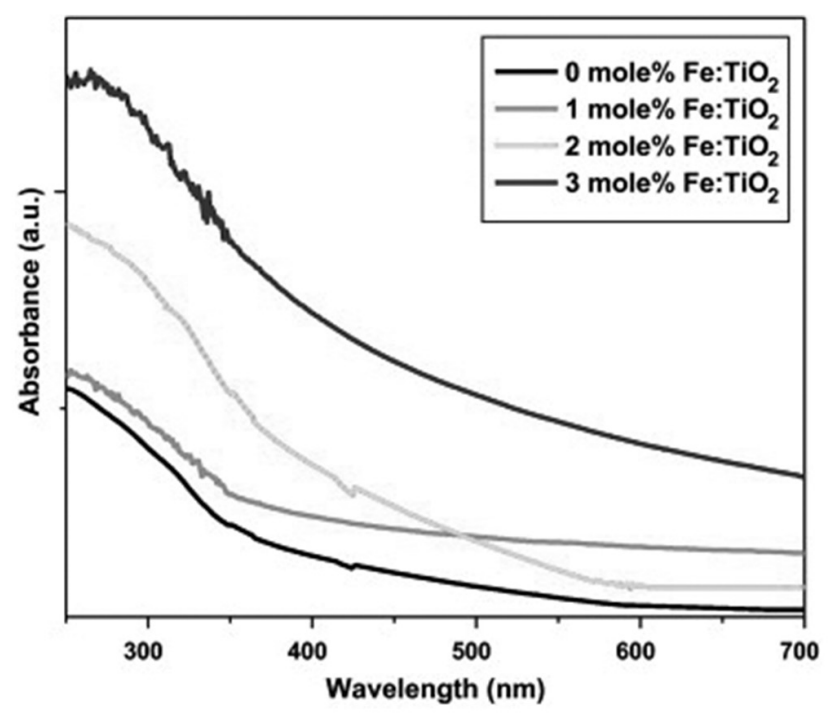

Figure 4. UV-vis spectra of representative Fe-doped $\mathrm{TiO}_{2}$ samples [6]

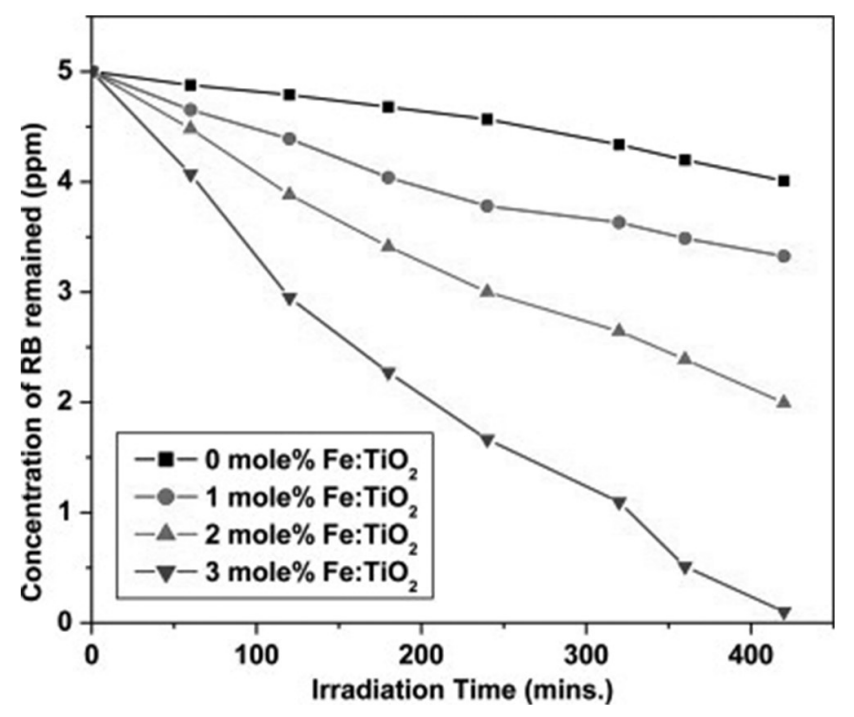

Figure 5. Change in the RB concentration after the use of suspension of iron into/onto $\mathrm{TiO}_{2}$ nanoparticles [6]

\section{Application of $\mathrm{TiO}_{2}$ in photocatalysis}

Photocatalysis gained a lot of attention in the environmental protection in the field of pollutants degradation/ conversion due to a growing need to develop new methods of the pollutants treatment in waste waters and/or air. Titania has a very important place among other photocatalysts because of its high photocatalytic activity, high chemical stability, thermal stability, excellent functionality and finally, it is a cost-effective catalyst. In the recent period, $\mathrm{TiO}_{2}$ has become an environmental photo-catalyst for a large variety of organic pollutants such as: various organic dyes (Bromocresol green, Azo dye, Orange II, Crystal violet), pesticides, antibiotics, xenobiotics (nitroaromatic compounds) identified in wastewater and air due to the industrial activity $[2,6,7,9,12,14]$.
Seabra et al. [2] examined photocatalytic degradation of Orange II solutions in the presence of $\mathrm{TiO}_{2}$ powders. In their research, they have concluded in their research that maximum decolouration attained in the case of the use of undoped $\mathrm{TiO}_{2}$ was $81 \%$, in the use of $\mathrm{Zn}$ doped titania $98 \%$ and when Fe doped titania was used it was $43 \%$. The Fe doped titania exhibited a tendency to agglomeration and this fact explained a decrease of photodegradation efficiency in that reported case [2]. A group of scientists investigated a photocatalytic conversion of $p$-nitrobenzaldehyde to $p$-nitrobenzoic acid using undoped and doped $\mathrm{TiO}_{2}$. The results showed that there was no conversion of $p$-nitrobenzaldehzde if the solution was irradiated in the absence of the catalyst, but the photocatalytic performance of the doped catalysts increased with the increase of the dopant amount (they used $1 \mathrm{~mol}$. $\%, 2 \mathrm{~mol}$. $\%$ and $3 \mathrm{~mol}$. $\%$ Fe to $\mathrm{TiO}_{2}$ ). The maximum conversion of $p$-nitrobenzaldehyde to $p$-nitrobenzoic acid for $3 \mathrm{~mol}$. \% Fe doped titania was attributed to the lowest band gap energy, the increase in the surface area and higher hydroxyl concentrations on the surface of the oxide surface [6].

The main parameters that affected the efficiency and rate of pollutant degradations are: characteristics and concentrations/dosages of the catalyst, the nature and concentration of pollutants, $\mathrm{pH}$, oxidants addition, light intensity and wavelengths [31].

\section{Influence of $\mathrm{pH}$}

$\mathrm{pH}$ is an important parameter that affects the photocatalytic degradation of organic pollutants. The value of $\mathrm{pH}$ determines the charging of the surface of the photocatalyst, potential hydrophobicity, (net)/surface charge of pollutants and the amount of generated hydroxyl radical. A group of scientists have been studied the effect of $\mathrm{pH}$ on the degradation of nitrobenzene using $\mathrm{TiO}_{2}$ suspension. They found that $\mathrm{pH}$ did not significantly affect benzene degradation, because unmodified benzene did not react with acid or base and was not ionized under different $\mathrm{pH}$ values [32]. In this study, the literature data showed that the maximum removal of organic pollutants was reached at $\mathrm{pH}$ between 6.5 and 7 . In this range of $\mathrm{pH}$, the pollutant, its degradation intermediates and the used catalyst were neutral; this situation favored the reactions of degradation and mineralization [33].

\section{Influence of Light Intensity and Wavelength}

A group of scientists organized comparative studies of photocatalytic degradation of nitrobenzene by using concentrated solar radiations or UV light in the same reactor [33]. The results showed that by using artificial UV lamp for $1 \mathrm{~h}$, nitrobenzene was completely removed, but it took $4 \mathrm{~h}$ to remove nitrobenzene by using solar irradiation. UV lamps can be replaced with solar light by using titania doped with transition metal(s) (Fe, Cu, $\mathrm{Zn}$ ) with the improved photocatalytic activity in a visible region; this suggested that waste water refining can drastically reduce the water cost and treatments costs [34]. 


\section{Conclusions}

Due to unique characteristics like a photocatalytic activity, excellent functionality, thermal stability, non-toxicity and cost-effectiveness, $\mathrm{TiO}_{2}$ is considered as the most thoroughly investigated semiconductor used as a photocatalyst in the literature. The sol-gel and hydrothermal methods are frequently used for the synthesis and also for modification of $\mathrm{TiO}_{2}$. Titania can be doped with metals, nonmetals and/or ionic components in order to enhance its photocatalytic activity and to extend the response into the visible domain of irradiation. In recent years, various transition metals have been used as dopants such as iron and/or zinc, and it has been proved that after doping of $\mathrm{TiO}_{2}$ under certain conditions, its properties can be significantly improved. A large number of researches confirmed that $\mathrm{TiO}_{2}$-assisted photocatalysis is an efficient method for degradation of different organic pollutants which can be applied for the conversion of toxic organic pollutants into less or non-toxic compounds.

\section{Acknowledgements}

The authors would like to thank to the Ministry of Education, Science and Technological Development for financial support (project TR 34008).

\section{List of abbreviations}

$\mathrm{TiO}_{2}$ - Titanium dioxide

$\mathrm{TiCl}_{4}$ - Titanium tetrachloride

$\mathrm{K}_{2} \mathrm{TiF}_{6}$ - Potassium hexafluorotitanate

$\mathrm{TiOSO}_{4}$ - Titanile sulfate

$\mathrm{Na}_{2} \mathrm{SO}_{4}$ - Sodium sulfate

$\mathrm{K}_{2} \mathrm{CO}_{3}-$ Potassium carbonate

$\left(\mathrm{NH}_{4}\right)_{2} \mathrm{CO}_{3}-$ Amonium carbonate

$\mathrm{Na}_{2} \mathrm{CO}_{3}$ - Sodium carbonate

$\mathrm{TiO}\left(\mathrm{NO}_{3}\right)_{2}$ - Titanium nitrate

$\mathrm{Ti}(\mathrm{OR})_{4}$ - Titanium alkoxides

$\mathrm{HCl}-\mathrm{Hydrochloric} \mathrm{acid}$

$\mathrm{HNO}_{3}-$ Nitric acid

$\mathrm{NH}_{4} \mathrm{OH}-$ Ammonium hydroxide

XRD - X-ray diffraction

SEM - Scanning electron microscopy

TEM - Transmission electron microscopy

FTIR - Fourier-transformed Infrared Spectroscopy

RhG - Rhodamine 6G

\section{References}

[1] S. Husain, L. A. Alkhtaby, E. Giorgetti, A. Zoppi, M. M. Miranda, Investigation of the role of iron doping on the structural, optical and photoluminescence properties of sol-gel derived $\mathrm{TiO}_{2}$ nanoparticles, Journal of Luminescence 172 (2016) 258-263.

[2] M. P. Seabra, I. M. Miranda Salvado, J. A. Labrincha, Pure and (zinc or iron) doped titania powders prepared by sol-gel and used as photocatalyst, Ceramics International 37 (2011) 3317-3322.
[3] I. J. Ani, U. G. Akpan, M. A. Olutoye, B. H. Hameed, Photocatalytic degradation of pollutants in petroleum refinery wastewater by $\mathrm{TiO}_{2-}$ and $\mathrm{ZnO}$-based photocatalysts: Recent development, Journal of Cleaner Production 205 (2018) 930-954.

[4] M. Raileanu, M. Crisan, I. Nitoi, A. Ianculescu, P. Oancea D. Crisan, A. Todan, $\mathrm{TiO}_{2}$-based nanomaterials with photocatalytic properties for the advanced degradation of xenobiotic compounds from water. A literature survey, Water Air Soil Pollut. 224 (2013) 1548.

[5] I. Vukoje, T. Tomašević llić, A. Zarubica, S. Dimitrijević, M Budimir, M. Vranješ, Z. Šaponjić, J. Nedeljković, Silver film on nanocrystalline $\mathrm{TiO}_{2}$ support: Photocatalytic and antimicrobial ability, Mater. Res. Bull. 60 (2014) 824-829.

[6] S. D. Delekar, H. M. Yadav, S. N. Achary, S. S. Meena, S. H. Pawar, Structural refinement and photocatalytic activity of Fe-doped anatase $\mathrm{TiO}_{2}$ nanoparticles, Applied Surface Science 263 (2012) 536-545.

[7] B. Babić, A. Zarubica, T. Minović Arsić, J. Pantić, B. Jokić, N. Abazović, B. Matović, Iron doped anatase for application in photocatalysis, Journal of the European Ceramic Society 36 (2016) 2991-2996.

[8] L-Y. Qiao, F-Y. Xie, M-H. Xie, C-H. Gong, W-L. Wang, J-C. Gao, Characterization and photoelectrochemical performance of $\mathrm{Zn}$-doped $\mathrm{TiO}_{2}$ films by sol-gel method, Trans. Nonferrous Met. Soc. China 26 (2016) 2109-2116.

[9] P. Goswami, J. Nath Ganguli, Evaluating the potential of a new titania precursor for the synthesis of mesoporous Fe-doped titania with enhanced photocatalytic activity, Materials Research Bulletin 47 (2012) 2077-2084.

[10] A. R. Gandhe, S. P. Naik, J. B. Fernandes, Selective synthesis of $\mathrm{N}$-doped mesoporous $\mathrm{TiO}_{2}$ phases having enhanced photocatalytic activity, Micropor. Mesopor. Mater. 87 (2005) 103

[11] J. A. Navio, G. Colon, M. Macias, C. Real, M. I. Litter, Irondoped titania semiconductor powders by a sol-gel method. Part I: synthesis and characterization, Applied Catalysis A: General 177 (1999) 111-120.

[12] M. Crisan, M. Raileanu, N. Dragan, D. Crisan, A lanculescu, I. Nitoi, P. Oancea, S. Somacescu, N. Stanica, B. Vasile, C. Stan, Sol-gel iron-doped $\mathrm{TiO}_{2}$ nanopowders with photocatalytic activity, Applied Catalysis A: General 504 (2015) 130-142.

[13] R. Janes, L. J. Knightley, C. J. Harding, Structural and spectroscopic studies of iron (III) doped titania powders prepared by sol-gel synthesis and hydrothermal processing, Dyes and Pigments, 62 (2004) 199-212.

[14] X. Vargas, E. Tauchert, J. M. Marin, G. Restrepo, R. Dillert D. Bahnemann, Fe-doped titanium dioxide synthesized: Photocatalytic activity and mineralization study for azo dye, Journal of Photochemistry and Photobiology A: Chemistry 243 (2012) 17-22.

[15] M. H. H. Mahmoud, A. A. Ismail, M. M. S. Sanad Developing a cost-effective synthesis of active iron oxide doped titania photocatalyst loaded with palladium, platinum or silver nanoparticles, Chemical Engineering Journal 187 (2012) 96-103.

[16] S. Liu, X. Liu, Y. Chen, R. Jiang, A novel preparation of highly active iron-doped titania photocatalyst with a n-p junkction semiconductor structure, Journal of Alloys and Compounds 506 (2010) 877-882.

[17] Z. M. Wang, G. Yang, P. Biswas, W. Bresser, P. Boolchand, Processing of iron-doped titania powders in flame aerosol reactors, Powder Technology 114 (2001) 197-204. 
[18] J. G. Mahy, S. D. Lambert, G. L.-M. Leonard, A. Zubiaur, P. Y. Olu, A. Mahmoud, F. Boschini, B. Heinrichs, Towards a large scale aqueous sol-gel synthesis of doped $\mathrm{TiO}_{2}$ : Study of various metallic dopings for the photocatalytic degradation of p-nitrophenol, Journal of Photochemistry and Photobiology A: Chemistry 329 (2016) 189-202.

[19] J. F. Duncan, R. G. Richards, Hydrolysis of titanium(IV)sulphate solutions: 2. Solution equilibria, kinetics and mechanism. New Zealand Journal of Science, 19 (1976) 179-183.

[20] E. Santacesaria, M. Tonello, G. Storti, R. C. Pace, S. Carra, Kinetics of titanium dioxide precipitation by thermal hydrolysis, Journal of Colloid and Interface Science, 111 (1986) 44-53.

[21] S. R. Dhage, S. P. Gaikwad, V. Ravi, Synthesis of nanocrystalline $\mathrm{TiO}_{2}$ by tartrate gel method, Bulletin of Materials Science, 27(6) (2004) 487-489.

[22] D. A. Ward, E. I. Ko, Preparing catalytic materials by the sol-gel method, Industrial and Engineering Chemistry Research, 34 (1995) 421-433.

[23] J. Livage, M. Henry, C.Sanchez, Sol-gel chemistry of transition metal oxides, Progress in Solid State Chemistry, 18 (1988) 259-341.

[24] M. Crişan, M. Raileanu, A. lanculescu, D. Crişan, N. Dragan, Sol-gel $\mathrm{TiO}_{2}$-based oxide systems. In R. E. Morris (Ed.), The sol-gel process: Uniformity, polymers and applications (pp. 1-135). New York: Nova Science Publishers, Inc. (2011b).

[25] H. Liu, L. Yu, W. Chen, Y. Li: „The progress of $\mathrm{TiO}_{2}$ nanocrystals doped with rare earth ions", Journal of Nanomaterials 2012 (2012) 235879 (9 pp).

[26] K. Byrappa, T. Adschiri, Hydrothermal technology for nanotechnology. Progress in Crystal Growth and Characterization of Materials, 53 (2007) 117-166.

[27] H.-B. Lu, Y.-Z. Zhou, S. Vongehr, S.-C. Tang, X.-K. Meng, Effect of hydrothermal temperature on formation and decoloration characteristics of anatase $\mathrm{TiO}_{2}$ nanoparticles, Science China Technological Sciences, 55 (4) (2012) 894-902.

[28] T.-D. N. Phan, H.-D. Pham, T. V. Cuong, E. J. Kim, S. Kim, E. W. Shin, A simple hydrothermal preparation of $\mathrm{TiO}_{2}$ nanomaterials using concentrated hydrochloric acid, Journal of Crystal Growth, 312 (2009) 79-85.

[29] B. Milićević, Modifikacija strukturnih, morfoloških i optičkih svojstava anataz $\mathrm{TiO}_{2}$ nanočestica dopiranjem trovalentnim jonima retkih zemalja, Thesis, Dept. of Physical Chemistry, University of Belgrade, 2017.

[30] M. Branković, A. Zarubica, T, Anđelković, D. Anđelković, Mesoporous silica (MCM-41): Synthesis/modification, characterization and removal of selected organic micropollutants from water, Advanced technologies, 6(1) (2017) 50-57.

[31] U. I. Gaya, A. H. Abdullah, Heterogenous photocatalytic degradation of organic contaminants over titanium dioxide. A review of fundamentals, progress and problems, Journal of Photochemistry and Photobiology C: Photochemistry Review, 9 (2008) 1-12.

[32] W. Bahnemann, M. Muneer, M. M. Haque, Titanium dioxide-mediated photocatalysed degradation of few selected organic pollutants in aqueous suspensions, Catalysis Today, 124 (2007) 133-148.

[33] D. Bhatkhande, V. Pangarkar, A. Beenackers, Photocatalytic degradation of nitrobenzene using titanium dioxide and concentrated solar radiation: chemical effects and scaleup, Water Research, 37 (2003) 1223-1230.

[34] X.-Z. Shen, Z.-C. Liu, S.-M. Xie, J. Guo, Degradation of nitrobenzene using titania photocatalyst co-doped with nitrogen and cerium under visible light illumination, Journal of Hazardous Materials, 162 (2009) 1193-1198.

Izvod

\section{HEMIJSKE MODIFIKACIJE NANOSTRUKTURNIH MATERIJALA NA BAZI TITAN(IV)-OKSIDA U FOTOKATALITIČKOJ RAZGRADNJI/KONVERZIJI RAZLIČITIH ORGANSKIH POLUTANATA: KRATAK PREGLED}

Aleksandra Krstić, Hristina Stanković, Miljana Rubežić, Marija Vasić, Aleksandra Zarubica

Prirodno-matematički fakultet, Univerzitet u Nišu, Niš, Srbija

Titan(IV)-oksid, kao fotokatalizator koji se može primenjivati za dekontaminaciju životne sredine, sve više dobija na značaju u uklanjanju organskih polutanata iz vode i vazduha. Za dobijanje $\mathrm{TiO}_{2}$ katalizatora se mogu koristiti različite metode, ali su sol-gel i hidrotermalna metoda najčešće korišćene za sintezu i modifikaciju $\mathrm{TiO}_{2}$. Osobine nanostrukturnih materijala kao što su: kristalne faze, površinska svojstva i elektronska struktura se mogu izmeniti dopiranjem. U ovom radu će biti razmatran, na bazi literaturnih podataka, uticaj Fe i Zn kao dopanata na fizičkohemijske osobine $\mathrm{TiO}_{2}$. Instrumentalne tehnike koje se najčešće koriste za karakterizaciju materijala su: XRD tehnika, SEM, TEM, FTIR i UV-vis spektroskopija. Efikasnost uklanjanja različitih organskih polutanata (organskih boja, antibiotika, pesticida, ksenobiotika) zavisi od karakteristika i doze/količine katalizatora koji se primenjuje, prirode i inicijalne koncentracije polutanta, vrednosti $\mathrm{pH}$, upotrebe oksidanasa, intenziteta elektromagnetnog zračenja i talasne dužine.
(PREGLEDNI RAD)

UDK 544.526.5:549.514.6+66.017

Ključne reči: Cink, Fotokataliza, Gvožđe, Hidrotermalna sinteza, Sol-gel, Titan(IV)oksid 